\title{
Balloon atrial septostomy in pulmonary arterial hypertension: A beneficial effect on the control of rhythm abnormalities
}

\author{
Katarzyna Malaczynska-Rajpold, Aleksander Araszkiewicz, \\ Tatiana Mularek-Kubzdela \\ $1^{\text {st }}$ Department of Cardiology, Poznan University of Medical Sciences, Poznan, Poland
}

\begin{abstract}
Pulmonary arterial hypertension $(\mathrm{PAH})$ results in volume overload of the right heart chambers. Chronically elevated right atrial pressure causes its remodeling and promotes supraventricular arrhythmias [1] - a factor of worse prognosis in this group [2].

The subject of the study was a 31-year-old man with idiopathic pulmonary hypertension with the history radiofrequency (RF) ablation of cavo-tricuspid isthmus due to macroreentry atrial tachycardias - repeated twice. From the time of diagnosis the patient was treated with treprostinil and sildenafil. His clinical state remained stable for several years in functional class II.

However, a progression of the disease with exacerbation of right ventricular failure and recurrence of atrial tachycardia (Fig. 1A) have been observed, in spite of increasing the dose of treprostinil. Recently, routinely performed tests revealed factors of worse prognosis: 6-minute walking distance $-260 \mathrm{~m}$, N-terminal pro B-type natriuretic peptide $-7,647 \mathrm{pg} / \mathrm{mL}$; in echocardiography right atrium area was $55 \mathrm{~cm}^{2}$ (Fig. 1C); in right heart catheterization: mean pulmonary artery pressure $43 \mathrm{~mm} \mathrm{Hg}$, mean right atrial pressure $-24 \mathrm{~mm} \mathrm{Hg}$, cardiac index $-1.6 \mathrm{~L} / \mathrm{min} / \mathrm{m}^{2}$, blood oxygen saturation in pulmonary artery $-59.6 \%$, pulmonary resistance $-19 \mathrm{WU}$. We considered next $\mathrm{RF}$ ablation procedure to stop the arrhythmia, but there was a strong suspicion that the arrhythmia is rather a result than a cause of the patient's clini-
\end{abstract}

cal deterioration $[2,3]$. Therefore we performed balloon atrial septostomy (BAS) to decrease right ventricle preload (Fig. 1D). Small decompressive hole in the interatrial septum was done stepwise using a balloon with a diameter of $4 \mathrm{~mm}$ and then $6 \mathrm{~mm}$. A pressure drop in the right atrium from $24 \mathrm{~mm} \mathrm{Hg}$ to $18 \mathrm{~mm} \mathrm{Hg}$ was achieved with a concomitant decrease in oxygen saturation of arterial blood to $90 \%$ and end-diastolic pressure in the left ventricle maintained at the level of $10 \mathrm{~mm} \mathrm{Hg}$. Mean pulmonary artery pressure fell to $41 \mathrm{~mm} \mathrm{Hg}$ during the procedure. An additional and unexpected benefit of this procedure was a restoration of sinus rhythm (Fig. 1B), which was maintained for a few months following the procedure and the patient's clinical state remained stable.

Ballon atrial septostomy is a known method used as a bridge to lung transplantation (LuTX) in patients with severe PAH and right ventricular failure with elevated right atrial pressure, however it may also be used as a palliative treatment for patients disqualified from LuTX to prolong their lives $[4,5]$. In the described case, such a reduction of right atrial pressure and sympathetic overactivity by the means of BAS [6] not only fulfilled the abovementioned role, but also showed another benefit - a relief from atrial tachycardia, which improved the patient's short-term prognosis $[2,3]$.

Conflict of interest: None declared

Address for correspondence: Katarzyna Malaczynska-Rajpold, MD, PhD, $1^{\text {st }}$ Department of Cardiology, Poznan University of Medical Sciences, ul. Długa 1/2, 61-848 Poznań, Poland, tel: +48 6185491 46, fax: +48 618549094 , e-mail: katarzyna.rajpold@skpp.edu.pl

Received: 01.07.2016 Accepted: 27.07.2016 


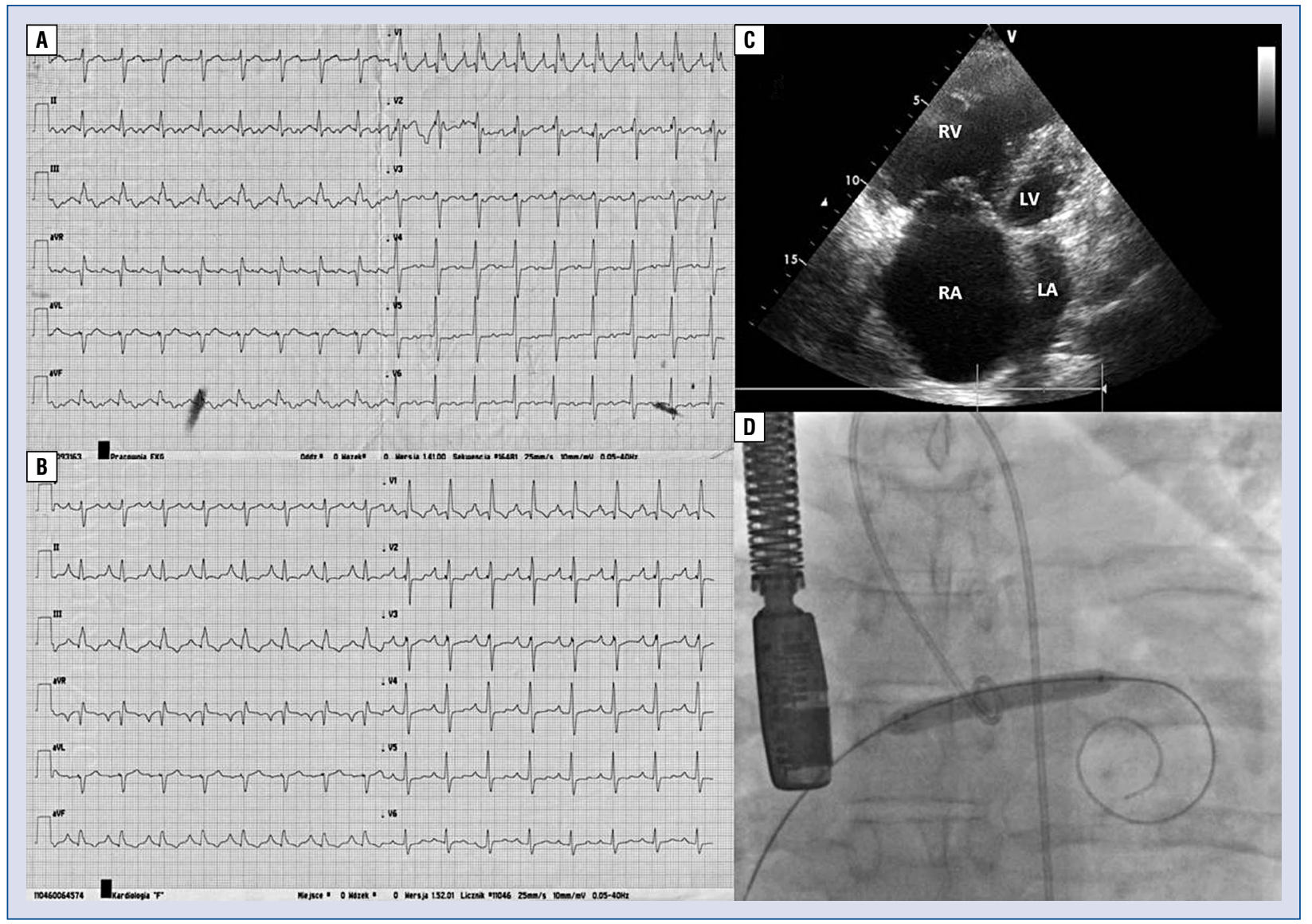

Figure 1. In a patient with severe pulmonary arterial hypertension; A. Electrocardiogram (ECG) with atrial tachycardia before balloon atrial septostomy (BAS); B. ECG with sinus rhythm restored by means of right atrial pressure reduction during BAS; C. Echocardiography: 4-chamber view shows severe enlargement of the right heart chambers; $\mathbf{D}$. BAS: inflation of a balloon to make a decompressive hole in the interatrial septum; RA — right atrium; LA — left atrium; RV — right ventricle; LV — left ventricle.

\section{References}

1. Medi C, Kalman JM, Ling L-H et al. Atrial electrical and structural remodeling associated with longstanding pulmonary hypertension and right ventricular hypertrophy in humans. J Cardiovasc Electrophysiol, 2012; 23: 614-620. doi:10.1111/j.15408167.2011.02255.x.

2. Adachi S, Hirashiki A, Nakano Y, Shimazu S, Murohara T, Kondo T. Prognostic factors in pulmonary arterial hypertension with Dana Point group 1. Life Sci, 2014; 118: 404-409. doi: 10.1016/j. lfs.2014.03.002.

3. Małaczyńska-Rajpold K, Komosa A, Błaszyk K et al. The management of supraventricular tachyarrhythmias in patients with pulmonary arterial hypertension. Hear Lung Circ, 2016; 25: 442-450. doi:10.1016/j.hlc.2015.10.008.

4. Kuhn BT, Javed U, Armstrong EJ et al. Balloon dilation atrial septostomy for advanced pulmonary hypertension in patients on prostanoid therapy. Catheter Cardiovasc Interv, 2015; 85: 1066-1072. doi:10.1002/ccd.25751.

5. Kurzyna M, Dabrowski M, Bielecki D et al. Atrial septostomy in treatment of end-stage right heart failure in patients with pulmonary hypertension. Chest, 2007; 131: 977-983. doi: 10.1378/ chest.06-1227.

6. Ciarka A, Vachièry J-L, Houssière A et al. Atrial septostomy decreases sympathetic overactivity in pulmonary arterial hypertension. Chest, 2007; 131: 1831-1837. doi:10.1378/chest.06-2903. 